\title{
Quantitative evidence for judgments on the efficacy of inoculation for the prevention of smallpox: England and New England in the 1700s
}

\author{
Edward Huth
}

J R Soc Med 2006;99:262-266

Additional material for this article is available from the James Lind Library website [www.jameslindlibrary.org] where this paper was previously published.

The introduction of inoculation for protection against smallpox in England in the early 1700s, and the gathering of quantitative data justifying its use, are a complex story. The best modern accounts of these developments are almost certainly those by two medical historians, Genevieve Miller $^{1}$ and Andrea Rusnock. ${ }^{2}$ This commentary draws on their accounts, primary sources they cite, and other cited sources.

Smallpox, whether epidemic or endemic, was a prominent cause of death in 18th century England. Data from that period indicate deaths from smallpox averaged roughly $10 \%$ as a percentage of all deaths in affected regions, but sometimes up to approximately 20\%. Greatly feared sequelae were severe disfigurement or blindness. Early in this century reports began to reach England through personal communications and formal documents that inoculating persons through skin incisions with material such as pustular matter from a patient with smallpox could prevent attacks of full-blown 'natural' smallpox. Especially influential reports were those of Emmanuel Timoni(us), an Italian physician, and Giacomo (Jacobus) Pylarinius, ${ }^{3}$ a graduate of medicine at Padua, to the Royal Society of London. Timonius's report, a 1713 letter to the Royal Society of London, was called to the attention of members of the Society by John Woodward's summary of the letter. ${ }^{4}$

'The Writer [Timonius] of this ingenious Discourse observes, in the first place, that the Circassians, Georgians, and other Asiaticks, have introduc'd this Practice of procuring the SmallPox by a sort of Inoculation, for about the space of forty Years, among the Turks and others at Constantinople.

That altho' at first the more prudent were very cautious in the use of this Practice; yet the happy Success it has been found to have in thousands of Subjects for these eight Years past, has now put it out of all suspicion and doubt; since the Operation having been perform'd on Persons of all Ages, Sexes, and different Temperaments, and even in the worst Constitution of the Air, yet none have been found to die of the Small-Pox; when at the same time it was very mortal when it seized the Patient the common way, of which half the affected dy'd. This he attests upon his own Observation.'

This practice was reported by others to be used in many other areas outside of western Europe, such as Greece, Armenia, and North Africa.

With such reports, the possibility of protecting persons against the risk of smallpox through inoculation became known among English physicians. But many were strongly reluctant to attempt this novel-for England - method of preventive treatment. It struck them as having a high risk of inducing a potentially fatal disease for which they had no clearly effective treatment. Some eminent members of the highest levels of London society were, or became, aware of the inoculations practiced in the Near East and sought inoculation in England for their children. Prominent among them was Lady Mary Wortley Montagu who became aware of inoculation when she was in Constantinople with her husband in his ambassadorial post. This excerpt from one of her letters represents her convictions.

‘. I am going to tell you a thing that I am sure will make you wish yourself here. The small-pox, so fatal, and so general amongst us, is here entirely harmless by the invention of ingrafting, which is the term they give it. There is a set of old women who make it their business to perform the operation every autumn. . . The old woman comes with a nut-shell full of the matter of the best sort of small-pox, and asks what veins you please to have opened. . . . She immediately rips open that you offer her with a large needle. . . and puts into the vein as much venom as can lie upon the head of her needle. . . . Every year thousands undergo this operation . . . There is no example of any one that has died in it; and you may believe I am well satisfied of the safety of the experiment. . . . I am patriot enough to take pains to bring this useful invention into fashion in England; and I should not fail to write to some of our doctors very particularly about it, if I knew any one of them that I 
thought had virtue enough to destroy such a considerable branch of their revenue for the good of mankind.' 5

She arranged with Charles Maitland, a Scottish surgeon for a time posted to the British Embassy in Constantinople, for inoculation of her daughter. It was successful in not causing full-blown smallpox and became widely known through social circles at her level. Caroline, Princess of Wales, a member of the royal family, became interested in this new development and the possibility of having her daughters inoculated. There were, of course, uncertainties about the safety of inoculation. She persuaded her father, George I, to prepare a pardon for condemned felons in Newgate prison if they were to volunteer to be inoculated as a test of safety. Arrangements were made for a trial on six prisoners in Newgate, ${ }^{6}$ three men matched for approximately the same ages with three women. All six survived and were pardoned. Indeed, Maitland arranged for a crude test of the efficacy of inoculation for the prevention of smallpox by having one of the women in the trial subsequently serve as a nurse to a young smallpox patient with whom she agreed to sleep. After 6 weeks of such exposure she had not fallen victim to smallpox.

In time more physicians became aware of successful inoculations and began to offer it. Such favourable views in the profession of this novel procedure were not, however, universal, and the profession split into those violently opposed to the procedure and those supporting it.

Data gathered on mortality due to smallpox inoculation in the first half of the 18th century in England represent what was probably one of the first major attempts in any country to judge the validity of a medical treatment from quantitative data. This was not the first effort in England to consider healthcare issues with substantial quantitative data. It clearly stood in the tradition stemming from numerical analysis of the London Bills of Mortality initiated in the 17th century by two London tradesmen, John Graunt and Sir William Petty, who created the notion of 'political arithmetic'.

Directly relevant to the arguments on inoculation was Dr John Arbuthnot's tabulation of smallpox mortality in London for the years 1707-1718 in the Graunt and Petty tradition $^{2}$ (pp. 45-9). His anonymously published tabulation was cast as a vindication of the practice as represented by Charles Maitland, the inoculator of Lady Montagu's daughter. Arbuthnot calculated that the mortality rate in smallpox was 1 in $10(10 \%)$ while estimating that from inoculation was only 1 in 100 (1\%). He did not, however, publish data supporting his estimate of inoculation mortality.

Maitland was for a while the only inoculator, but other physicians and surgeons joined in. By 1722 at least 182 persons had been inoculated in England by physicians, surgeons, apothecaries, and a small number of inoculators of unidentified vocation. Among these was a physician in Halifax, Yorkshire, Dr. Thomas Nettleton. He had read the paper by John Woodward ${ }^{4}$ in the Philosophical Transactions of the Royal Society of London on the report from Timonius and, probably, Pylarinius's account published in $1716 .^{3}$ Nettleton was also aware of the Newgate experiment. Facing an outbreak of smallpox in his region he decided to try this preventive measure. By 1722 Nettleton had inoculated at least 40 people in Halifax and neighboring towns. He initially reported his experiences in 'A Letter from Dr. Nettleton, Physician at Halifax in Yorkshire, to Dr. Whitaker, concerning the Inoculation of the Small Pox' published in the Philosophical Transactions of the Royal Society of London; ${ }^{7}$ but he did not publish his initial data on the differences in mortality between inoculation cases and 'natural' cases until later in $1722 .{ }^{8}$

II would only . . . leave to remark, that it appears from these Accounts, that this last Year, in this Part of the Kingdom, almost nineteen out of every hundred, or near one fifth of those, who have had the natural Small Pox, have died; whereas out of sixty one which have been inoculated hereabouts, not one has died . . .

Preceding this passage is Nettleton's tabulation of cases of smallpox in his region in the preceding year and the number of resulting deaths-3405 cases with 636 deaths (a mortality rate of $18.8 \%$ ) - these data being the basis for his 'near one fifth . . . who have had the natural Small Pox, have died'. The death rate in inoculated cases was $0 \%$ !

Favourable views were held not only in England. In Boston, New England, an eminent non-physician, Cotton Mather, and a physician colleague, Dr Zabdiel Boylston, became strong supporters of inoculation. A terrible smallpox epidemic broke out in Boston in $1721^{9}$ that stimulated Boylston to inoculate persons in an attempt to prevent their becoming infected. Mather had heard of inoculation from his African slave-servant and, through his being a corresponding Fellow of the Royal Society, had read of inoculation in the Philosophical Transactions. Hence Mather was supportive of Boylston in his efforts. Boylston travelled to London in 1725 and reported his data on inoculated persons to the Royal Society. His data became more widely known through his published account; ${ }^{10}$ a table in it reports a low mortality among inoculated persons in the Boston region: of 247 persons inoculated by Boylston in 1721 and 1722, only six died (a mortality of $2.4 \%$ ).

The strongest effort to judge the safety of inoculation was launched by the physician and mathematician, Dr James Jurin, Secretary of the Royal Society under Isaac Newton's presidency. Having become aware of Nettleton's data, he invested himself in developing a large correspondence 
network to gather data from other sources on mortality from inoculationed smallpox that could be compared with data on mortality from 'natural' smallpox. With his mathematical background it is not surprising that he became seen as a 'staunch advocate for the appreciation of mathematics to medical topics'2 (p. 49). In a letter to Dr Caleb Cotesworth ${ }^{11}$ he reported the mortality rate from smallpox estimated from English sources as 856 deaths out of 4626 cases $(18.5 \%)$. His letter summarizes his conclusions on the mortality rates from natural smallpox and inoculation in various categories:

'The Result . . . Of these Computations is, that, if the same Proportions should still continue, as have hitherto been determin'd by Observation, we must expect,

That of all the Children that are born, there will, some time or other, die of the Small Pox, one in fourteen.

That of Persons of all Ages taken ill of the natural Small Pox, there will die of that Distemper, one in five or six, or two in eleven.

That of Persons of all Ages inoculated, without regard to the Healthiness or Unhealthiness of the Subject, as was practised in New England, there will die one in sixty.

That of Persons inoculated with the same Caution in the choice of the Subjects, as has been used by the several Operators one with another, here in England, (if we allow in the two disputed Cases above mention'd, that the Persons died of the inoculated Small Pox) there will die one in ninety one.'

Jurin continued to collect data and publish them. In 1726 he published $^{12}$ the data he had accumulated, including those for 1725. The total for persons ill with smallpox was 17 151 and for those who died of smallpox 2848; a 'hazard nearly one in six' (16.6\% mortality). Of 481 inoculated in 1725 and preceding years, 10 were 'suspected to have died of inoculations', or 1 of 48 (2.1\% mortality). His report published in $1727^{13}$ gives the cumulative figures for the same categories: 2927 deaths from smallpox among 18089 ill with smallpox (16.3\% mortality) and of those inoculated in 1726, one death from suspected smallpox among 105 inoculees (1.0\% mortality).

At the end of 1727 Jurin lost his post of Secretary of the Royal Society of London and discontinued collecting data on natural smallpox and inoculation. His kind of analysis was continued by Dr John Gaspar Scheuchzer, a Swiss who had become the librarian of Sir Hans Sloane, who succeeded Newton as President of the Royal Society. Scheuchzer shortly after. His paper ${ }^{14}$ was published by Sloane later that year.

On page 9 of his report, Scheuchzer states precisely and succinctly in the form of questions what might be answered by the data gathered by Jurin:

1. Whether the Distemper given by Inoculation be an effectual Security to the Patient against his having the Small-Pox in the natural Way?

2. Whether the Hazard of Inoculation be considerably less than that of the natural Small-Pox?

On his page 13 he reviews the data of Jurin already published and some additional data available to him pertinent to the mortality rate in natural smallpox. Among 18229 people 'Sick of the Small-Pox' 3008 died, 'one in six' (16.5\%), 'which, considering the Largeness of the Numbers, we may lay down for the Hazard of the natural Small-Pox'.

Scheuchzer's table on page 24 summarizes the data, including those collected by Jurin, for people inoculated in the years 1721 through 1728. Those inoculated totalled 897. Of these, 845 were judged to have had smallpox from the inoculation, 13 had 'an imperfect Small-Pox', 39 'showed no effect', and 17 were 'supposed to have died'. If one assumes that the 39 represents people with either a technically inadequate inoculation or a prior immunity, the mortality rate from inoculation was 17 among 858 inoculees (a mortality rate of $2 \%$ ). Hence the second question posed by Scheuchzer was answered affirmatively. The first, however, was not. Jurin and Scheuchzer did not have data from long-term follow ups on whether any inoculated people later developed 'natural' smallpox.

Jurin's and Scheuchzer's data did not end controversies over the propriety and efficacy of smallpox inoculation. Much of the opposition was based on religious grounds, but eventually inoculation became widely accepted. As Miller notes $^{1}$ (p. 168), 'In spite of sporadic opposition . . . there is no doubt that the smallpox pandemic of 1752 provided the final stimulus necessary to fix inoculation securely in the English medical armament'.

Inoculation was also practiced in the American colonies, but the only data on post-inoculation mortality reported after Boylston's appear to be those of Benjamin Franklin. ${ }^{15}$ He had been asked by the eminent London physician, William Heberden, for data on the consequences of inoculation in the American colonies. His report was based on the inoculations stimulated by a Boston outbreak of smallpox in 1753 or 54 . He reported for the Boston region that of 5059 'whites' who contracted smallpox 'in the common way', 452 died (a mortality rate of $8.9 \%$ ). Of 485 'blacks' similarly infected, 62 died (a mortality rate of 12.8\%). Of 1974 'whites' inoculated, 23 died (a mortality 
rate of $1.2 \%$ ); of 139 'blacks' inoculated, seven died (a mortality rate of $5.0 \%)$. He did not have exact numbers for Philadelphia but reports that of 'upwards of 800 [inoculated] . . . only four died (a maximum mortality rate of $0.5 \%)$.

From today's perspective, the data gathered by Nettleton, Jurin, Scheuchzer, and others are imperfect proof of the efficacy of inoculation in preventing death from natural smallpox in that they did not know the exposure period or rate for inoculated persons. The general acceptance of the view that inoculation did offer protection from the 'natural infection' may have been based, in large part, on the anecdotal evidence reported from southeastern Europe and the Near East. Was there any quantitative evidence from those regions that supported the efficacy of inoculation before the English efforts to gather relevant data? Probably not, concludes a historian of medicine with expertise on medicine in some of those regions [Moulin A-M, Personal communication, 2 April 2005].

'[As far as I know, there was no] discussion of the mortality and morbidity rates in relation to inoculation [in those regions] ... There are no vital statistics before the first census which took place after the beginning of smallpox vaccine which is a different matter. Even in this case, like in Egypt, or the Ottoman Empire, where you have [a] census in the first part of the XIXth century, you do not have registration of smallpox inoculation, and you only have some registration of smallpox vaccine, a fortiori, you have no compared estimation of both. In the end of the XIXth century, you have statistics of vaccination, and inoculation goes on in the countryside but in a hidden way, again without any statistics. . . . There are texts in arabic in Egypt and Tunisia on the reception and religious validity of inoculation and vaccination, but none to the best of my knowledge on the statistical debate.'

Given the high incidence of natural smallpox in England in the 18th century, efficacy does seem to have been reasonably well established. So the data gathered and analysed in the 1720s did represent numerical (quantitative) evidence for efficacy of a preventive treatment. But there was a growing awareness through the rest of the 18th century in England of the need for prospective trials adequately designed to yield fully convincing quantitative data for judgments on treatments. In this period, various views of this need have been described by Tröhler. ${ }^{16}$

The efforts of Nettleton, Jurin, and Scheuchzer were a full century before Pierre Louis' advocacy of 'la méthode numerique' (numerical method) as he used it in studying the therapeutic value of bloodletting. Further, the procedure followed by Jurin, of accumulating as many data as possible, antedates by more than a century Jules Gavarret's explicit statistical calculations demonstrating in 1840 in his Principes Généraux de Statistique Médicale ${ }^{17}$ (p. 246) the greater certainty of a reliable conclusion with greater numbers of data.

In the view of a highly vocal English opponent of smallpox inoculation, those of Isaac Massey, apothecary to Christ's Hospital, London, Jurin's main argument in favour of inoculation was flawed and therefore not meaningful. In his $A$ Letter to Dr. Jurin ${ }^{18}$ he explained.

‘. I believe, upon Enquiry, it would be found, that above one half of those who die of the Small Pox, within the Bills of Mortality, are of the helpless Sort, whose Condition is infinitely worse than the Inoculated, and therefore no Computation can be admitted between them; if so, your Computation will amount to instead of One in Nine, to One in Eighteen, or thereabouts: But to state this Matter rightly, it must be remembred, That your Computations are of two Sorts; the First shews, that one in Fourteen, or a Fourteenth Part of all Mankind dies of the Small Pox the other, Page Thirteenth, shows, That out of every Nine Persons, young or old, poor or rich, taken with the natural Small Pox, one must die, or two out of Seventeen. I have nothing to object here, against these Computations, but as misapplyed in the present Case, and when your Comparison is reduced to Reason, for comparanda non debent habere magnum inter se Differentiam, it will appear, that not above One in Forty that have the Small Pox, would die of that Distemper, if treated with equal Care with those that are inoculated: but to form a just Comparison, and calculate right in this Case, the Circumstances of the Patients, must and ought to be as near as may be on a Par.'

Massey's point here relies on his assuming that those with natural smallpox may not have been 'treated with equal care' - care equaling that given to inoculated persons. He might have also pointed to possible nutritional differences between those with a 'natural case' of smallpox and inoculees. He may have been right on the 'equal care' issue, in that inoculation in the earliest years of the practice was given largely to the upper classes and mortality rates for 'natural cases' came from the wider population. The point he implies about the need for having all characteristics of cases in the two arms (naturally infected and inoculated) except for the 'treatment' (inoculation) and 'control cases (naturally infected) is sound, but he does not make it explicitly. Such control of homogeneity in comparisons of two or more arms of therapeutic assessments was attempted years later with case-control studies. However, the problem of heterogeneity of cases posed by Massey was eventually dealt with satisfactorily only in the second half of the 20th century, with the randomization of assignment to arms of a trial and subsequent statistical analysis of the effectiveness of randomization in distributing case differences efficiently in the two arms. 


\section{REFERENCES}

1 Miller G. The Adoption of Inoculation For Smallpox In England And France, Philadelphia: University of Pennsylvania Press, 1957

2 Rusnock AA. Vital Accounts: Quantifying Health And Population In Eighteenth-Century England And France. Cambridge: Cambridge University Press, 2002

3 Pylarinus J. Nova \& tuta variolas excitandi per transplantationem, nuper inventa \& in usum tracta. Phil Trans $R$ Soc Lond 1716;29:393-9. [Cited in Miller (see Ref. 1), p 60. Also: Pylarini J. A new and safe method of communicating the small-pox by inoculation, lately invented and brought into use. Translated and abridged from the Latin. In: Phil Trans R Soc Lond from their commencement, in 1665, to the year 1800,Abridged, Vol. VI from 1713 to 1723. London: L \& R Baldwin, 1809: 207-10]

4 Woodward J. An account, or history of the procuring the small pox by incision of inoculation, as it has for some time been practised at Constantinople. Phil Trans R Soc Lond 1714;29:72-92

5 Montagu MW. To Mrs. S. C [Miss Sarah Chiswell]. In: The Letters And Works Of Lady Mary Wortley Montagu. Lord Wharncliffe, ed [her greatgrandson]. New York: AMS Press, 1970 [Reprint of the 1861 edn]

6 Sloane H. An account of inoculation. Phil Trans $R$ Soc Lond 1756; 49:516-20

7 Nettleton T. A letter from Dr. Nettleton, physician at Halfax in Yorkshire, to Dr. Whitaker, concerning the inoculation of the small pox. Phil Trans $R$ Soc Lond 1722-1723;32:35-8

8 Nettleton T. Part of a letter from Dr. Nettleton, physician at Halifax, to Dr. Jurin, R. S. Sec concerning the inoculation of the small pox, and the mortality of that distemper in the natural way. Phil Trans $R$ Soc Lond 1722-1723;32:209-12

9 Aronson SM, Newman L (2002). God have mercy on this house: being a brief chronicle of smallpox in colonial New England [http://www. brown.edu//Administration/News_Bureau/2002-03/02-017t.html] Accessed 21 June 2005

10 Boylston Z. Historical Account Of The Small-Pox Inoculated In New-England, Upon All Sorts Of Persons, Whites, Blacks, And Of All Ages And Constitutions: With Some Account of The Nature Of The Infection In The Natural And Inoculated Way, And Their Different Effects On Human Bodies: With Some
Short Directions To The Unexperienced In This Method Of Practice. Humbly Dedicated To Her Royal Highness The Princess Of Wales, 2nd edn. London: Printed for S. Chandler, at the Cross-Keys in the poultry, 1726

11 Jurin J. A letter to the learned Dr. Caleb Cotesworth, F.R.S. of the College of Physicians, London, and physician to St. Thomas's Hospital; containing a comparison between the danger of the natural small pox, and that given by inoculation. Phil Trans R Soc Lond 1724;32:213-27

12 Jurin J. An Account Of The Success Of Inoculating The Small-Pox In Great Britain, For The Year 1725: With A Comparison Between The Miscarriages In That Practice, And The Mortality of The Natural Small-Pox. London: J Peele, 1926

13 Jurin J. An Account Of The Success Of Inoculating The Small-Pox In GreatBritain, For The Year 1726. With A Comparison Between The Miscarriages In That Practice, And The Mortality Of The Natural Small-Pox. London: J Peele, 1927

14 Scheuchzer JG. An Account Of The Success Of Inoculating The Small-Pox In Great Britain, For The Years 1727 And 1728: With A Comparison Between The Mortality of The Natural Small-Pox, And The Miscarriages In That Practice; As Also Some General Remarks On Its Progress And Success, Since Its First Introduction. London: J Peele, 1929

15 Franklin B. Some Account Of The Success Of Inoculation For The Small-Pox In England And America. Together With Plain Instructions, By Which Any Person May Be Enabled To Perform The Operation And Conduct The Patient Through The Distemper. London: W Strahan, 1759

16 Tröhler U. Quantifying experience and beating biases: A new culture in eighteenth-century British clinical medicine. In: Jorland G, Opinel A, Weisz G, eds. Body Counts: Medical Quantification in Historical and Sociological Perspective. Montreal, London, Ithaca: McGill University Press, 2005:19-50

17 Gavarret J. Principes Généraux De Statistique Médicale. Paris: Bechet jeune et Labé, 1840

18 Massey I. A Short And Plain Account Of Inoculation. With Some Remarks On The Main Argument Made Use Of To Recommend That Practice, By Mr. Maitland And Others. To Which Is Added, A Letter To The Learned James Jurin, M. D. R. S. Secr. Col. Reg. Med. Lond. Soc. In Answer To His Letter To The Learned Dr. Cotesworth, And His Comparison Between The Mortality Of Natural And Inoculated Small Pox. London: W Meadows, 1723 